\title{
Programme Evaluation of Post Graduate Certificate in Endodontics Programme of Indira Gandhi National Open University: A Learner's Perspective
}

\section{Amiteshwar Ratra* and Anita Priyadarshini}

Associate Professor, Staff Training and Research Institute of Distance Education, Indira Gandhi National Open University, New Delhi, India

*Corresponding author: amiteshwar@ignou.ac.in

Received: 17 Oct., 2020

Revised: 23 Nov., 2020

Accepted: 06 Dec., 2020

\begin{abstract}
Programme Evaluation is a very important aspect of Open and Distance Learning (ODL) institutions. Programme evaluation is considered an essential part for quality assurance. This paper focuses on the programme evaluation study of Post Graduate Certificate in Endodontics (PGCE) programme offered bySchool of Health Sciences of Indira Gandhi National Open University, New Delhi, India. Dental education with passage of time has achieved greater salience in the present times. The programme evaluation of study Post Graduate Certificate in Endodontics programme of Indira Gandhi National Open University was conducted as a felt need to analyze the academic, and operational aspects of this unique programme and for further policy making related to suchdental programmes. Mixed method was used to collect data from learners. Both primary data and secondary data was collected and analyzed. The findings showed that the self-learning material (SLMs) of PGCE were found to be of a high quality. Learners agreed that the face-to-face academic counseling for practical work through the study centres located in reputed dentalcolleges had to be a mandatory requirement. The need for recognition of the programme by the statutory body ie Dental Council of India was also considered the "most important" factor for their enrolment in such a programme. It was felt by the participants that the PGCE programme through openand distance learning (ODL) provided an opportunity for dentist to upgrade their knowledge and skills while continuing to pursue their practice. The participation of learners in the PGCE programme them more confident in handling endodontic cases.
\end{abstract}

Keywords: Dental education, distance learners, open and distance learning, programme evaluation

How to cite this article: Ratra, A. and Priyadarshini, A. (2020). Programme Evaluation of Post Graduate Certificate in Endodontics Programme of Indira Gandhi National Open University: A Learner's Perspective. Learning Community, 11(2): $101-114$. 
The Indira Gandhi National Open University (IGNOU) is national university with international presence. The meaning of 'Programme' as adopted by IGNOU implies courses being taught with some theme or purpose leading to a degree or diploma with set standards. (Handbook on Programme Evaluation, 2006). Knox (2002) pointed out that for programme evaluation all the persons involved in course development, design, delivery, administration, and collaboration need to be involved. Gaba and Dash (2004) conducted a case study on the Post Graduate Diploma in Higher Education and found that there was need to update of self-instruction materials. In another study, Fozdar (2010) found that IGNOU had succeeded in providing quality science education in India to students from across various sections.

\section{Significance for the Study}

The Post Graduate Certificate in Endodontics (PGCE) dental programme was developed and launched in July 2008 in collaboration with Dental Council of India (DCI). The DCI is the Dental Statutory bodyfor conducting Dentistry programms. The evaluation of the PGCEprogramme was under taken as it had been implemented for over 5 years since the launch of the programme.

Specific Objectives of the study were as follows:

To find out the demographic profile of the PGCE learners;

To examine the design and development of the programme with respect to self-learning materials;

To examine the student support services provided to the PGCE learners; and

To study the impact of the programmes upon the professional growth of learners.

\section{Methodology}

A research design is a systematic plan to study a scientific problem. For the present study, a descriptive sample survey was adopted using mixed method approach (Creswell, 2012). Population for Post Graduate Certificate in Endodontics was all the students enrolled in this programme from the year of launch of the programme.

Content analysis was done of the documents related to this programme. The phase forms of the launch of the programme were analyzed. A total of 403 numbers of students had enrolled for Post Graduate Certificate in Endodontics programme since inception of the programme in 2008. All these constituted the sample for the document analysis of the present study. In addition interview were held with students in study centers located in selected dental collages. As the sample size was less than 30 , only percentages (\%) were used. Graphical representation of the data was made.

To validate the questionnaire, it was emailed to randomly selected 11 learners enrolled for the programme. Content validation of the questionnaires were done by the experts from dental field, School (SOHS) 
Experts, Planning and Development Division, experts from the Programme Evaluation field from IGNOU and few external experts. After receiving the feedback, the questionnaires were revised and finalized for the present study.

\section{RESULTS AND DISCUSSION}

The present study reflects the results obtained after analysis of documents related to design and development of the PGCE programme, the available data and the focus group interviews conducted in the field. A determined effort was made by the evaluators to obtain responses, 24 responses were received.

\section{Objective 1: To find out the demographic profile of the PGCE learners}

\section{Analysis of Learner Profile from Admission Data}

Document analysis of the data provided by Student Registration Division, IGNOU was done. It was found that the total number of students enrolled for PGCE were 403 of which 253 were females. Maximum learners belonged to the age group of 25-30 years. Maximum students were from Delhi region. It was seen that many learners had not provided their authentic email address and phones numbers. The email addresses of 231 learners andmobile numbers of 227 learners were provided by the learners. The analysis of the above-mentioned data is as below:

Table 1: Sex of learners

\begin{tabular}{lll}
\hline Sex & Number of learners & Percentage \\
\hline Male & 150 & $37.2 \%$ \\
Female & 253 & $62.8 \%$ \\
\hline
\end{tabular}

Table 2: Age of learners ( $\mathrm{N}=$ Number of learners who had entered their date of birth entered in data were 122)

\begin{tabular}{lll}
\hline Age Group & Frequency & Percentage \\
\hline Below 25 & 10 & $8.1 \%$ \\
$25-30$ & 77 & $63.1 \%$ \\
$31-35$ & 20 & $16.3 \%$ \\
$36-40$ & 12 & $9.8 \%$ \\
Above 41 & 3 & $2.4 \%$ \\
\hline
\end{tabular}


D Ratra and Priyadarshini

Table 3: State-wise distribution of learners based upon their postal addresses

\begin{tabular}{|c|c|c|}
\hline City & Frequency & Percentage \\
\hline Andhra Pradesh & 24 & $5.9 \%$ \\
\hline Assam & 5 & $1.2 \%$ \\
\hline Bihar & 7 & $1.7 \%$ \\
\hline Chandigarh & 1 & $0.2 \%$ \\
\hline Chattisgarh & 1 & $0.2 \%$ \\
\hline Dadar and Nagar Haveli & 1 & $0.2 \%$ \\
\hline Delhi & 78 & $19.3 \%$ \\
\hline Gujarat & 15 & $3.7 \%$ \\
\hline Haryana & 20 & $4.9 \%$ \\
\hline Himachal Pradesh & 9 & $2.2 \%$ \\
\hline $\mathrm{J} \& \mathrm{~K}$ & 4 & $0.9 \%$ \\
\hline Karnataka & 28 & $6.9 \%$ \\
\hline Kerala & 36 & $8.9 \%$ \\
\hline Madhya Pradesh & 16 & $3.9 \%$ \\
\hline Maharashtra & 55 & $13.6 \%$ \\
\hline Manipur & 1 & $0.2 \%$ \\
\hline Orrisa & 3 & $0.7 \%$ \\
\hline Pondicherry & 2 & $0.4 \%$ \\
\hline Punjab & 8 & $1.9 \%$ \\
\hline Rajasthan & 20 & $4.9 \%$ \\
\hline Sikkim & 1 & $0.2 \%$ \\
\hline Tamil Nadu & 42 & $10.4 \%$ \\
\hline Uttar Pradesh & 22 & $5.4 \%$ \\
\hline Uttaranchal & 2 & $0.4 \%$ \\
\hline West Bengal & 8 & $1.9 \%$ \\
\hline
\end{tabular}

Table 4: E-mail IDs of learners entered in database

\begin{tabular}{lll}
\hline Learners & Frequency & Percentage \\
\hline Total in SRD database & 403 & \\
E-mail provided by learners & 231 & $57.3 \%$ \\
\hline
\end{tabular}


Table 5: Contact numbers of learners entered in database

\begin{tabular}{lll}
\hline Learners & Frequency & Percentage \\
\hline Total in SRD database & 403 & \\
Contact Numbers provided by learners & 227 & $56.3 \%$ \\
\hline
\end{tabular}

Feedback from Learners based upon Questionnaire /Field Work

\section{Learner Profile}

The maximum respondents were in the age group of 25-30 years Maximum feedback was received from students enrolled in Maulana Azad Institute of Dental Sciences (MAIDS), Delhi (36.3\%). Most of the respondents had completed their programme (more than 95.4\%) and were in private practice with only a single respondent serving in Government sector. Majority of the respondents joined this programme to upgrade their knowledge and skills and for career advancement. The results have been presented in below mentioned tables and graphs.

Table 6: Distribution of Programme Study Centres from where the response of PGCE learners was received

\begin{tabular}{lll}
\hline Programme Study Centre & Frequency & Percentage \\
\hline MAIDS, Delhi & 8 & $33 \%$ \\
GDC, Mumbai & 1 & $4 \%$ \\
GDC, Ahmedabad & 1 & $4 \%$ \\
GDC, Rohtak & 1 & $4 \%$ \\
Rangoonwala, Pune & 1 & $4 \%$ \\
R. Ahmed, Kolkata & 3 & $13 \%$ \\
SDM, Dharwad & 2 & $8 \%$ \\
Pacific Dental, Udaipur & 1 & $4 \%$ \\
VS Dental, Bangalore & 1 & $4 \%$ \\
Bapujj Dental Bangalore & 5 & $21 \%$ \\
\hline
\end{tabular}

Table 7: Status regarding completion of Programme

\begin{tabular}{lll}
\hline Status & Frequency & Percentage \\
\hline Completed & 23 & $96 \%$ \\
Still in process of completing & 0 & $0 \%$ \\
Drop Outs & 1 & $4 \%$ \\
\hline
\end{tabular}


Table 8: Status of Present Employment

\begin{tabular}{lll}
\hline Employment Status & Frequency & Percentage \\
\hline Private Clinic & 17 & $71 \%$ \\
Government Service & 1 & $4 \%$ \\
NGO & 0 & $0 \%$ \\
Any other & 6 & $25 \%$ \\
\hline
\end{tabular}

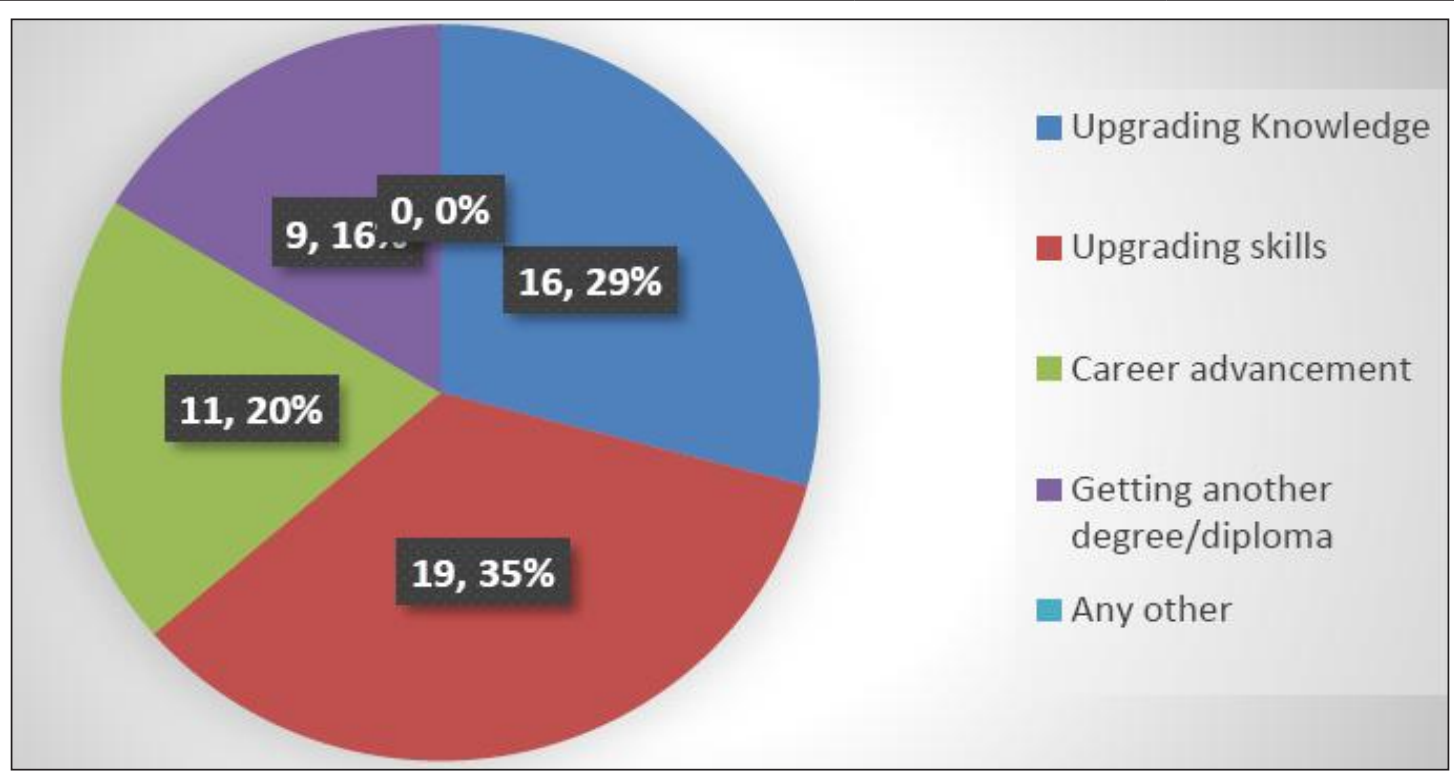

Fig. 1: Reason for joining the course

\section{Objective 2: To examine the design and development of the programme with respect to self-learning materials}

During document analysis, the procedure for approval of initiation of a programme was examined the documents examined included the Phase Forms, Programme Guide and Course Materials. After examining into these documents, it was found that timely approvals were taken by the School for the launch of programme as per IGNOU norms. The study of document related to Phase Forms revealed that all four Phase forms were duly completed and approved by the Statutory Bodies of IGNOU.

\section{Content analysis of Self-Learning Material of PGCE}

It was observed that all the Units (chapters) in each Coursewere developed based on the principles of instructional design for self learning material. They contained Structure, Check your Progress exercises and their answers. In each chapter/unit, objectives were well defined. Introduction of the chapter was 
written in a format to motivate the learner to read further. Self-instructional design was learner centered, communication in first person with use of words like "you", "we", etc. The distance education purports the study material to be learner oriented, self-instructional, promoting self-learning. Further readings were provided at the end of each unit for student's future reference. Units contained relevant diagrams wherever required.

The distance education purports the study material to be learner oriented, self-instructional, promoting self-learning. This was evident in the materials.

The interaction in the field also revealed that the course materials for PGCE were easy to understand and learner friendly. Field functionaries felt that though there was a need to update the materials, yet the course material of this PGCE programme was of high quality. The development of this professional programme by the SOHS, IGNOU was highly appreciated.

\section{Learners Feedback regarding Course Material}

The course material was rated excellent by almost maximum of the respondents in terms of readability (40.9\%), sequencing $(27.2 \%)$, organization $(27.2 \%)$, comprehension $(27.2 \%)$ and relevance $(31.8 \%)$. Although all of them (95.4\%) with the exception of $4.5 \%$ learners referred some additional books for their preparation and knowledge.

Table 9: Ratings on the Course Material

\begin{tabular}{llllll}
\hline & Excellent & Very good & Good & Satisfactory & Needs improvement \\
\hline Readability & 11 & 9 & 4 & 0 & 0 \\
Sequencing & 7 & 12 & 4 & 1 & 0 \\
Organization & 7 & 8 & 8 & 1 & 0 \\
Comprehension or Understanding & 7 & 10 & 4 & 3 & 0 \\
Relevance & 8 & 6 & 7 & 0 & 3 \\
\hline
\end{tabular}

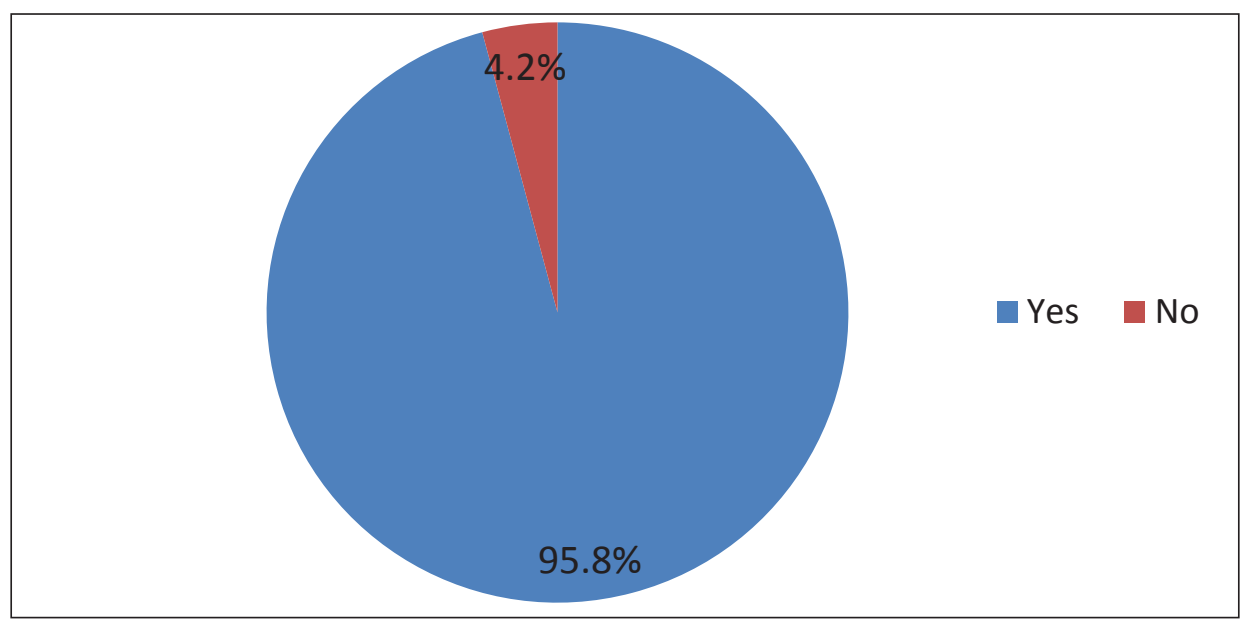


Fig. 2: Any other books referred apart from IGNOU study material

\section{Objective 3: To examine the student support services provided to the PGCE learners}

\section{Learners Feedback regarding Academic Counseling}

It was noted that, $70.8 \%$ respondents were of the view that theory counselling sessions should be made as compulsory requirement in the programme. The learners overall were satisfied with the academic counselling taking place at their study centers.

Table 10: Requirement of theory sessions

\begin{tabular}{lll}
\hline Response & Frequency & Percentage \\
\hline Yes & 17 & $70.8 \%$ \\
No & 3 & $12.5 \%$ \\
No response & 4 & $16.7 \%$ \\
\hline
\end{tabular}

\section{Learners Feedback Regarding Assignments}

Assignments were found to be up to the mark in terms of difficulty (59\%) and length wise (68.1\%) and mostly respondents agreed that assignments were useful for reinforcement and providing feedback (72.7\%). 68.1\% of respondents found evaluation of assignments very reliable and helpful in preparation of examination $(90 \%)$.

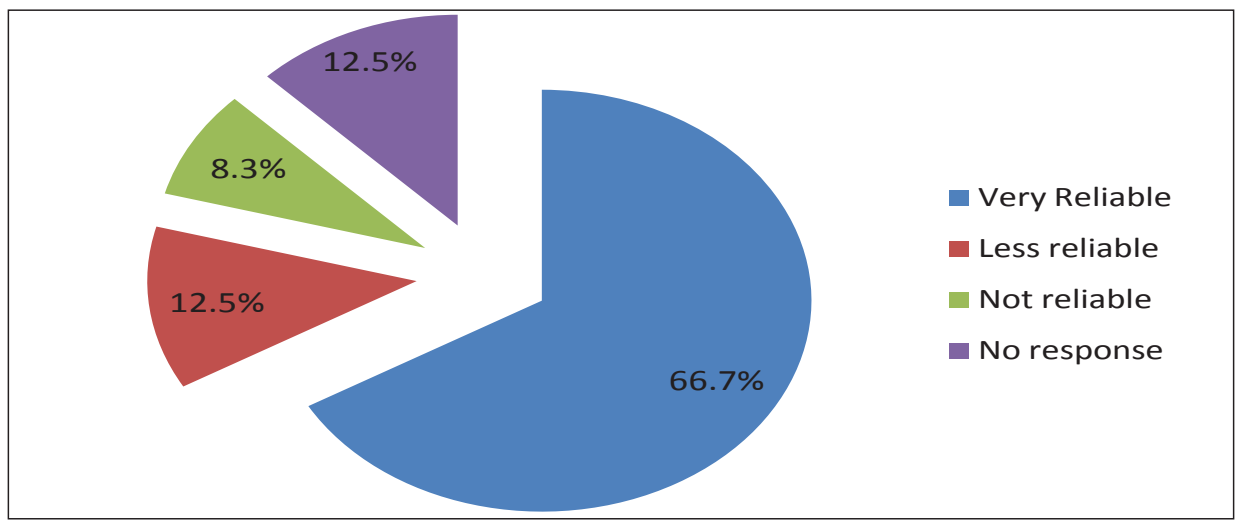

Fig. 3: Evaluation of Assignments

\section{Learners Feedback Regarding Support Services}

It was seen that $91 \%$ of the respondents, expressed their satisfaction with the timely replies from the Programme Coordinator related to various learner support quarries. Only 27.2\% responded that their exam results were not declared on time. $68.1 \%$ responded that they received regular support from 
Regional Centre officials. Almost all the students $(81.8 \%)$ received their study material on time while $13.6 \%$ students did not answer the question.

Table 11: Timely reply to student queries from the Programme Coordinator at IGNOU

\begin{tabular}{lll}
\hline Response & Frequency & Percentage \\
\hline Yes & 18 & $75.0 \%$ \\
No & 3 & $12.5 \%$ \\
No response & 3 & $12.5 \%$ \\
\hline
\end{tabular}

Table 12: Term end exam results declared on time

\begin{tabular}{lll}
\hline Response & Frequency & Percentage \\
\hline Yes & 16 & $66.7 \%$ \\
No & 6 & $25.0 \%$ \\
No response & 2 & $8.3 \%$ \\
\hline
\end{tabular}

Table 13: Support of IGNOU officials at the Regional Centre

\begin{tabular}{lll}
\hline Response & Frequency & Percentage \\
\hline Yes & 16 & $66.7 \%$ \\
No & 5 & $20.8 \%$ \\
No response & 3 & $12.5 \%$ \\
\hline
\end{tabular}

Table 14: Study Material received on time before examinations and start of practicals

\begin{tabular}{lll}
\hline Response & Frequency & Percentage \\
\hline Yes & 19 & $79.2 \%$ \\
No & 1 & $4.2 \%$ \\
No response & 4 & $16.7 \%$ \\
\hline
\end{tabular}

As for teleconferencing sessions, most of the respondents (54.5\%) found it useful although few of them (22.7\%) did not find the teleconferencing sessions useful.

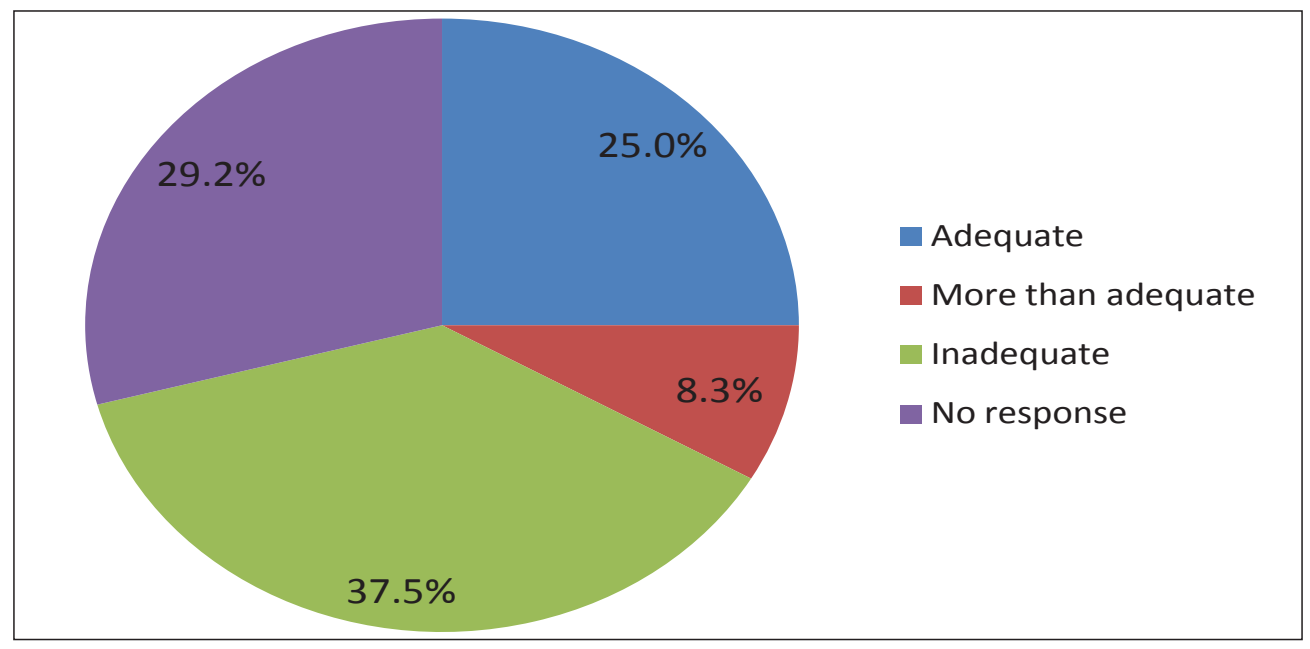


Fig. 4: Adequacy of Teleconferencing Sessions

\section{Learners Feedback Regarding Library}

Maximum of the respondents (72.7\%) expressed satisfaction with the library facility provided in their centre.

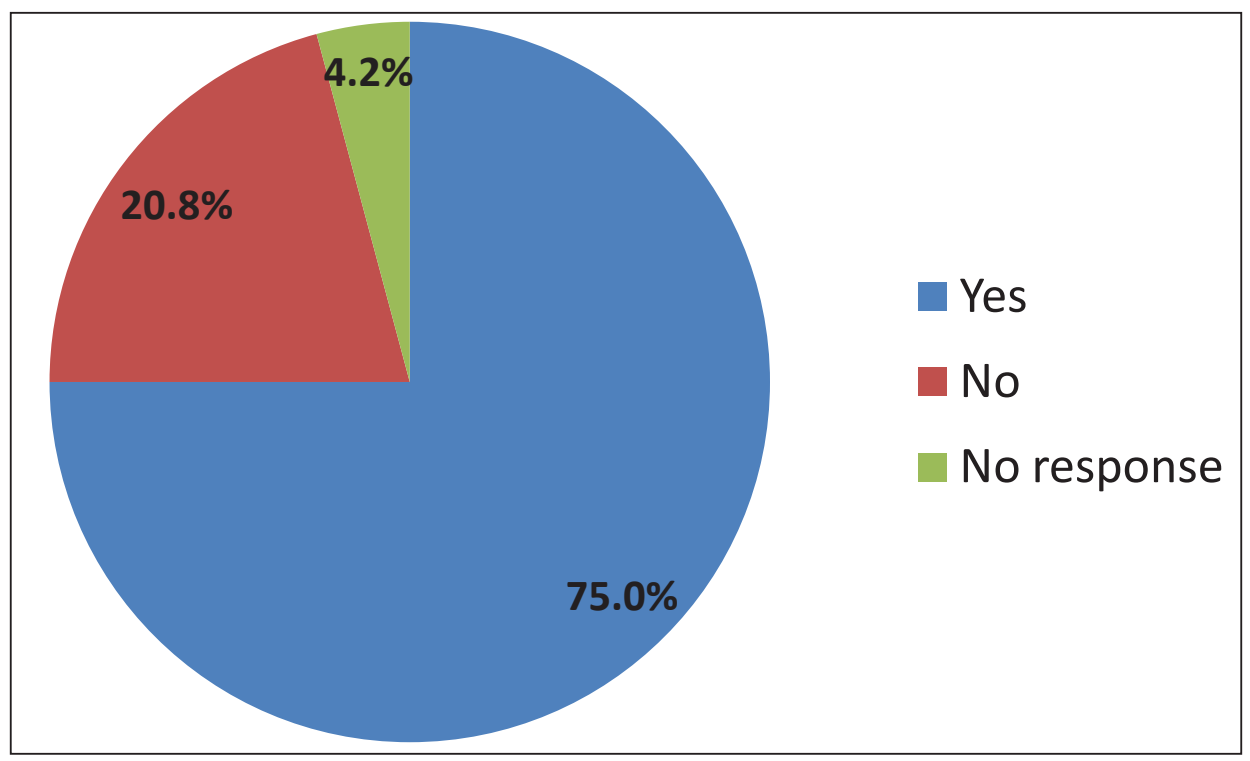

Fig. 5: Learners Feedback Regarding Library facilities at PSC

\section{Learners Feedback Regarding DCI Reorganization of the Programme}

This prgoramme was an outcome of the collaboration between IGNOU and Dental Council of India (DCI). All the learners (100\%) informed that they had enrolled in PGCE because it was a IGNOU-DCI programme. As many as $86.3 \%$ agreed that recognition/support of DCI in this programmewas "Most Important'for them as dental practitioners.

Objective 4: To study the impact of the programmes upon the professional growth of learners

\section{Learners Feedback Regarding Impact of the Programme}

As regards the increase of number of patients after completing the programme, 18.1\% learners said that there was an increase of $25-50 \%$ while $36.3 \%$ felt that the increase was $75-100 \% .22 .7 \%$ did not respond. $91 \%$ of the learners felt more confident in handling the Endodontic cases. 91\%\% learners 
rated the programme between good and excellent.

\section{FINDINGS}

This study is based upon the documents available at SOHS and the data available at IGNOU in the form of student admissions record and evaluation record as well as the data collected from the field at Programme Study Centres in and around Delhi. The study was limited to collecting the data largely through email due to paucity of resources.

\section{Learner Profile}

As per admission data, it is seen that, 403 students were admitted in this programme between July 2008 till July 2012.

Out of the total learners admitted in PGCE programme, 37.2\% were males and $62.7 \%$ were females.

Maximum number of students (19.3\%) admitted in this programme belonged to Delhi region followed by Maharashtra (13.6\%) based on address.

Regarding age, it was seen that only 122 out of 403 learners had provided details about their age. Accordingly, the maximum learners i.e., $63.1 \%$ are in the age group of 25 to 30 while $16.3 \%$ were in the age group of 31-35.

$84.3 \%$ learners provided their email address.It was suggested that providing authentic email and phone numbers must be made mandatory for learners.

Maximum number of learners (11.9\%) applied for admission under Bangalore Regional Centre

\section{Programme Development and Course Materials}

The Programme Guide outlined the programme structure and content and gave details of the programmes. However, the objectives of the programme were not clearly stated.

The procedure for development of material was followed as per the norms of the University. Phase forms were developed and necessary Expert Committees were constituted for development of self-learning materials.

The feedback from learners revealed that the materials were largely excellent in terms of readability and were very good in terms of sequencing, organization and comprehension. In terms of relevance, it was suggested that the materials be updated and revised to keep them abreast of the latest clinical developments.

The status of IGNOU programme offered through Open and Distance Learning (ODL) mode as 
compared to Continuing Dental Education programmes offered by other institutes/organizations was considered more practical oriented with better efficiency and impact.

As regards the counselling which till now it been done only for practical sessions, $70.8 \%$ learners were of the view that theory counselling sessions should be introduced in the programme.

Learners also appreciated the assignment and $72.7 \%$ found them useful for reinforcement and providing feedback.

\section{Student Support Services}

On the whole $66.7 \%$ learners were satisfied regarding the student support service and felt that the IGNOU officials at Regional Centres provided them the necessary support.

Based upon the questionnaires received back from learners, it was seen that the study materials were also received in time by $79.2 \%$ of the learners.

As for teleconferencing sessions, $50.0 \%$ of the learners found it useful. However, $12.5 \%$ did not attend the teleconferencing and $29.2 \%$ did not find it useful.

$75 \%$ learners availed the library facility in their respective programme study centre.

During the evaluation, it was observed that out of the top 15 Dental Colleges in India as identified by the Outlook Magazine, $1^{\text {st }}$ July, 2013, eight (08) of these were Programme Study Centres for IGNOU Dental Programmes.

\begin{tabular}{lll}
\hline Sl. No. & Name of Institute & IGNOU Centers \\
\hline 1 & Maulana Azad Inst of Dental Sciences, Delhi & PGCE \\
2 & Manipal College of Dental Sciences, Manipal & PGCE \\
3 & Government Dental College, Mumbai & PGCE \\
4 & Nair Hospital Dental College, Mumbai & PGCE \\
5 & Faculty of Dental Sc, King George's, Lucknow & PGCE \\
6 & PG Institute of Dental Sciences, Rohtak & PGCE \\
7 & SDM College of Dental Sciences, Dharwad & PGCE \\
8 & Bapuji Dental College \& Hospital, Davengere & PGCE \\
\hline
\end{tabular}

Source: Outlook Magazine (1 ${ }^{\text {st }}$ July, 2013).

\section{Impact of the Programme}

As regards the increase of number of patients after completing the programme, $18.1 \%$ learners said that there was an increase of $25-50 \%$ while $36.3 \%$ felt that the increase was $75-100 \%$. 
$22.7 \%$ did not respond.

91\% of the learners felt more confident in handling the Endodontic cases.

$91 \% \%$ learners rated the programme between good and excellent.

The importance of recognition by statutory body, Dental Council of India, was most important for conduct of this programme.

\section{CONCLUSION}

The PGCE programme was a unique programme meant for those who are in the field of dentistry. This programme was offered through ODL mode and was successful in benefitting those who wanted to upgrade their knowledge and skills. The role of dental colleges as study centres of IGNOU for this programme helped the learners as they continued to remain within their workplace and also study at the same time. The course materials prepared by SOHS was well appreciated as were the support services of study centres and SOHS. On the whole, the programme was found to be useful by the learners. The role of statutory body for recognizing such programmes is important so that successful, learners can emerge as successful and recognized practitioners in this field.

\section{Limitations}

This study was conducted on the PGCE programme and efforts were made to ensure that maximum response is obtained from the learners. However, it was observed that the response was very low, due to which the results of the study were affected. The findings and conclusion were based upon this response.

\section{ACKNOWLEDGEMENTS}

This paper is based upon the programme evaluation study of PGCE programme conducted by the authors. We express our sincere thanks to Director, STRIDE, IGNOU for financial support. We thank Director, School of Health Sciences (SOHS) and Prof. (Dr.) Ruchika Kuba, Programme Coordinator (Post Graduate Certificate in Endodontics, PGCE) for facilitating this challenging task. We were supported in our work by Dr. Deepak Monga, Consultant, STRIDE. We express our gratitude to the learners who participated in the study.

\section{REFERENCES}

1. Creswell, J. 2012. Educational research: Planning, conducting, and evaluating quantitative and qualitative research ( $4^{\text {th }}$ ed.). Upper Saddle River, NJ: Pearson Education.

2. Fozdar, Bharat, I. 2010. Project Report on Evaluating the BSc programme of IGNOU, submitted to DEC, IGNOU, New Delhi.

3. Gaba, A.K. and Dash, N.K. 2004. Course Evaluation in Open Distance Learning: A Case Study from Indira Gandhi National Open University, Open Learning, 19(2): 213-221. 
D Ratra and Priyadarshini

4. IGNOU website http://www.ignou.ac.in. Retrieved on 11.11.2013.

5. Knox, A.B. 2002. Evaluation for continuing education. New York: Wiley.

6. $\quad$ Outlook Magazine, 2013. $1^{\text {st }}$ July 2013, New Delhi. Retrieved on 11.11.2013.

7. Pradhan, B. and Mythili, G. 2006. Programme Evaluation in Open and Distance Education, New Delhi: STRIDE, IGNOU.

8. Priyadarshini, A. and Ratra, A. 2014. Report of the Programme Evaluation of Post Graduate Certificate in Oral Implantology (PGCOI), New Delhi: STRIDE, IGNOU (unpublished).

9. Programme Guide for Post Graduate Certificate in Endodontics (PGCE), School of Health Science, IGNOU. Retrieved on 10.11.2013.

10. STRIDE (2006) Manual for Programme and Course Coordinators, STRIDE, (IGNOU)Vice-Chancellor report (26 ${ }^{\text {th }}$ Convocation April 2013) IGNOU. 